\title{
Upper oesophageal sphincter yield pressure in normal subjects and in patients with gastro-oesophageal reflux
}

\author{
C. STA NCIU a n d J OH N . B E N N T T T \\ Gastro-intestinal Unit, Hull Royal Infirmary
}

\begin{abstract}
Stanciu, C. and Bennett, J. R. (1974). Thorax, 29, 459-462. Upper oesophageal sphincter yield pressure in normal subjects and in patients with gastro-oesophageal reflux. Upper oesophageal sphincter yield pressure was measured in 26 normal subjects and in 69 patients with gastro-oesophageal reflux, using a system of continuously perfused catheters. There was no significant difference between the two groups. Perfusion of the oesophagus with hydrochloric acid produced no change in sphincter pressure. The resting sphincter pressure was not related to the degree of oesophagitis nor to the severity of reflux as measured by 15 -hour $\mathrm{pH}$ recordings. There were significant differences in sphincter pressure recorded by the three catheters either when their orifices were set $5 \mathrm{~cm}$ apart longitudinally or when they were at the same level, equidistant around the circumference of a circle. This indicates that spatial orientation of catheter tips influences the pressure recorded from a sphincter.
\end{abstract}

The upper oesophageal sphincter (cricopharyngeal sphincter) has received less attention than the lower oesophageal sphincter, although studies of its normal and abnormal behaviour have been published (Lund, 1965; Code and Schlegel, 1967; Hunt, Connell, and Smiley, 1970; Ellis, 1971; Winans, 1972). Hunt et al. (1970) suggested that its resting pressure was higher in patients with gastro-oesophageal reflux than in normal subjects.

In this paper we examine the relationships between the resting upper sphincter yield pressure, the degree of oesophagitis, and the severity of gastro-oesophageal reflux.

\section{MATERIALS AND METHODS}

Studies were made of 26 normal volunteers (16 men, 10 women) aged 18-41 years (mean 32.1) and of 69 patients (39 men, 30 women) aged 17-70 years (mean $40.8)$ with heartburn and acid regurgitation related to posture and meals. Among the latter group radiology showed 21 to have hiatus hernia and/or gastrooesophageal reflux.

Sphincter pressure was measured with three polyvinyl catheters $(1.2 \mathrm{~mm}$ internal diameter) bound together with single side-holes $5 \mathrm{~cm}$ apart. The catheters were continuously perfused with distilled water at a rate of $0.8 \mathrm{ml} / \mathrm{min}$ by a syringe pump and were connected to Bell and Howell transducers, the output of which was recorded on a Devices M.19 multichannel direct-writing recorder. Respiration was monitored by a belt pneumograph. The catheters were passed via the nose into the stomach. With the patient supine and the transducers level with the posterior axillary line, they were then withdrawn in steps of $0.5 \mathrm{~cm}$. Once a catheter tip was in the pharynx, perfusion was stopped to prevent coughing. In each subject the mean upper sphincter pressure was calculated (taking end-expiratory oesophageal pressure as zero).

In eight normal subjects and six patients with reflux the manometric characteristics of the upper sphincter were studied with three continuously perfused catheters whose side-openings were at the same level, equidistant around the circumference of a circle.

In six normal subjects and nine patients with reflux, the sphincter pressure was measured with the proximal catheter stationary in the sphincter for a three-minute basal period, and for another three minutes while $30 \mathrm{ml}$ of $0 \cdot 1 \mathrm{~N}$ hydrochloric acid were dripped into the oesophagus through the distal catheter, $10 \mathrm{~cm}$ below the sphincter.

Oesophagoscopy (using an Olympus GIF or EF end-viewing fibreoptic instrument) was carried out without anaesthesia in 54 subjects and the degree of oesophagitis was graded as:

$\mathbf{O}=$ no oesophagitis (normal endoscopic appearance)

$A=$ mild oesophagitis (reddening of the mucosa)

$\mathbf{B}=$ severe oesophagitis (severe inflammation, bleeding, ulceration). 
A 15-hour continuous recording of the lower oesophageal $\mathrm{pH}$ was performed in 16 normal subjects and in all patients with reflux symptoms. Intraoesophageal $\mathrm{pH}$ was measured by a combined glass and reference pH electrode (GK 282C) with Radiometer pH meter (type PHM 26) the output of which was recorded on a direct-writing recorder at a constant speed. The $\mathrm{pH}$ electrode was passed through the nose and placed $5 \mathrm{~cm}$ above the lower oesophageal sphincter, the exact distance being known from the previous manometric studies. Once the $\mathrm{pH}$ electrode was positioned correctly, it was firmly anchored to the patient's cheek with adhesive tape, and a continuous record was made for 15 hours $(6 \mathrm{pm}$ to $9 \mathrm{am})$. A 'reflux episode' was defined as any occasion on which oesophageal $\mathrm{pH}$ dropped by $2 \mathrm{pH}$ units or more from the base-line of 6.0 to 6.5 . The proportions of total recording time during which the $\mathrm{pH}$ was less than 5,4 , and 3 were each calculated as percentages.

\section{RESULTS}

UPPER OESOPHAGEAL SPHINCTER PRESSURE (Fig. 1) In normal subjects the mean sphincter pressure was $43 \cdot 1 \pm \mathrm{SD} 13 \cdot 2 \mathrm{~cm} \mathrm{H}_{2} \mathrm{O}$, as compared with $41.5 \pm \mathrm{SD} 14.7 \mathrm{~cm} \mathrm{H}_{2} \mathrm{O}$ in patients with reflux, the difference being statistically not significant $(P>0.05)$. In both groups the range of pressures recorded was broad.

Perfusion of the oesophagus with acid caused no significant change in sphincter pressure (33.3 \pm SD

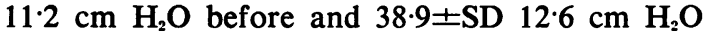
during instillation of acid).

The tracings obtained with the catheters having their orifices at an identical level and equidistant around the circumference of a circle showed a significant difference in sphincter pressure between the three leads, the variation (taking the greatest difference between any two of the three recording catheters) being 4 to $29 \mathrm{~cm} \mathrm{H}_{2} \mathrm{O}$.

There was no significant difference in the mean sphincter pressure between those with no oesophagitis $\left(41.0 \pm 11.6 \mathrm{~cm} \mathrm{H}_{2} \mathrm{O}\right)$ and those with mild $\left(41 \cdot 6 \pm 16.3 \mathrm{~cm} \mathrm{H}_{2} \mathrm{O}\right)$ or severe $(49 \cdot 2 \pm 18.2 \mathrm{~cm}$ $\mathrm{H}_{2} \mathrm{O}$ ) oesophagitis (Fig. 2).

There was no correlation between the severity of reflux, as recorded by $\mathrm{pH}$ electrode, and the sphincter pressure ( $r=0.067)$ (Fig. 3).

\section{DISCUSSION}

It has been suggested that the resting upper oesophageal sphincter pressure in patients with reflux was higher than in normal subjects, the raised pressure representing a response to the acid irritation and an attempt to prevent reflux into the pharynx (Hunt et al., 1970). Our results do not support this view, as we found the sphincter

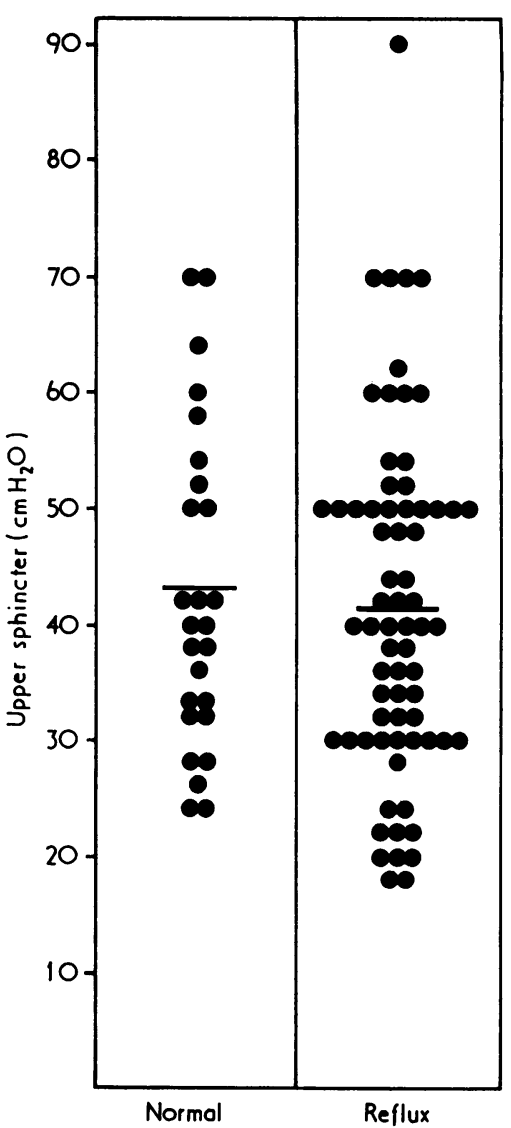

FIG. 1. Cricopharyngeal sphincter pressures in normals and patients with gastro-oesophageal reflux. Mean values indicated by horizontal bar.

pressure in patients with reflux no different from that in normal subjects; in both groups there was a wide range of pressure. We further extended the study by measuring lower oesophageal pH over an extended period, thus assessing the severity of reflux; we found no correlation between cricopharyngeal sphincter pressure and the degree of reflux as determined by this method. Moreover, the presence of hydrochloric acid in the mid-oesophagus made no difference to upper sphincter pressure in the short term. The likely reason for the discrepancy between the findings of Hunt et al. and our own, apart from population variation, is the different technique for measuring sphincter pressure.

Following the work of Winans and Harris (1967) and Pope (1967) it has become accepted that accurate and reproducible measurement of sphincter 'squeeze', over a wide range of pres 
Upper oesophageal sphincter yield pressure

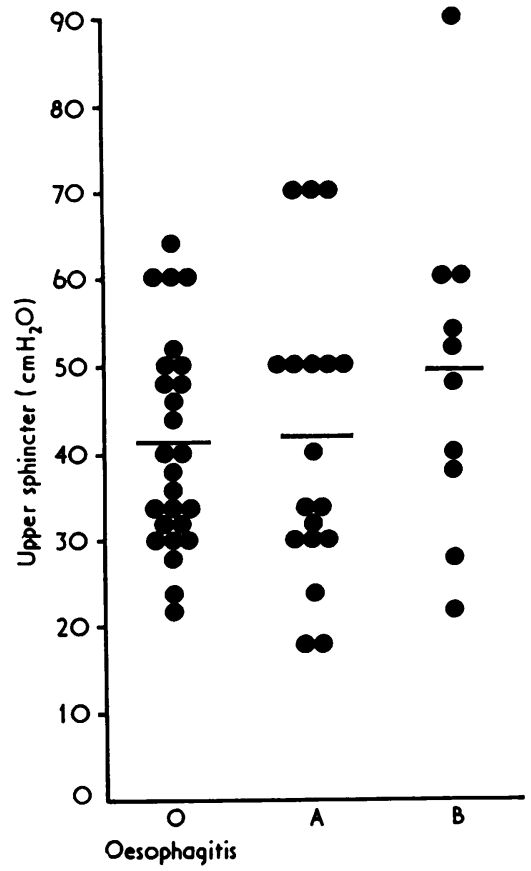

FIG. 2. Cricopharyngeal sphincter pressures in subjects with different degrees of oesophagitis ( $O=$ no oesophagitis; $A=$ mild oesophagitis; $B=$ severe oesophagitis).

FIG. 3. Lack of correlation between cricopharyngeal sphincter pressure and degree of reflux (measured as percentage of 15-hour lower oesophageal $\mathrm{pH}$ recording below $\mathrm{pH}$ 5) $\mathrm{r}=0.067$.

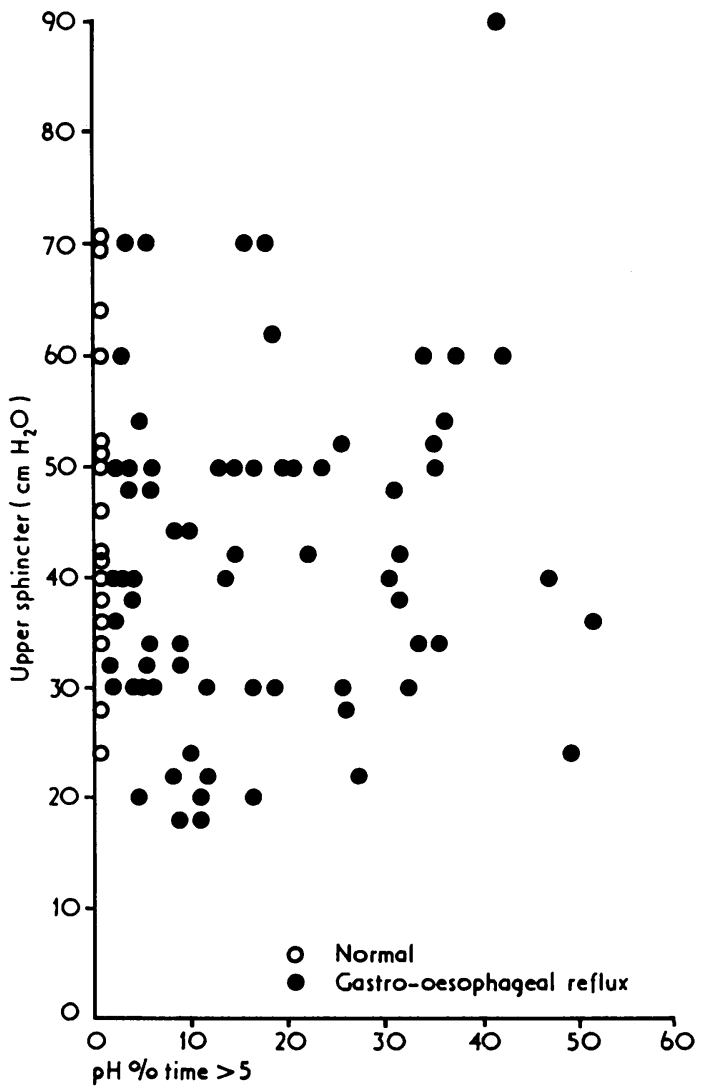


sures, can only be achieved by a system in which the pressure-recording catheters are continuously perfused with fluid; this measures the 'yield pressure' of the sphincter. We used such a perfused system, whereas Hunt et al. employed unperfused catheters which may give misleading readings of sphincter pressure.

We further demonstrated that manometric measurement of sphincter pressure using perfused catheters may be affected by the spatial orientation of the catheter side-hole having previously observed the same phenomenon in the lower oesophageal sphincter. This observation has been recorded by Winans (1972), who found no difference between cricopharyngeal sphincter pressure in normal subjects and those with symptoms of gastro-oesophageal reflux.

Our studies suggest that gastro-oesophageal reflux is unlikely to play a major role in the aetiology of pharyngeal diverticula through the mechanism of changes in cricopharyngeal sphincter pressure.

\section{REFERENCES}

Code, C. F. and Schlegel, J. F. (1967). Motor action of the esophagus and its sphincters. Handbook of Physiology-Alimentary Canal, Section 6, Vol. 4, Chapter 90, pp. 1821-1839. American Physiological Society, Washington, D.C.

Ellis, F. H. Jr. (1971). Upper esophageal sphincter in health and disease. Surgical Clinics of North America, 51, 553.

Hunt, P. S., Connell, A. M., and Smiley, T. B. (1970). The cricopharyngeal sphincter in gastric reflux. Gut, 11, 303.

Lund, W. S. (1965). A study of the cricopharyngeal sphincter in man and in the dog. Annals of the Royal College of Surgeons of England, 37, 225.

Pope, C. E. (1967). A dynamic test of sphincter strength: its application to the lower esophageal sphincter. Gastroenterology, 52, 779.

Winans, C. S. (1972). The pharyngoesophageal closure mechanism: a manometric study. Gastroenterology, 63, 768.

- and Harris, L. D. (1967). Quantitation of lower esophageal sphincter competence. Gastroenterology, 52, 773.

Requests for reprints to: Dr. John R. Bennett, Gastro-intestinal Unit, Hull Royal Infirmary, Hull HU3 2J. 